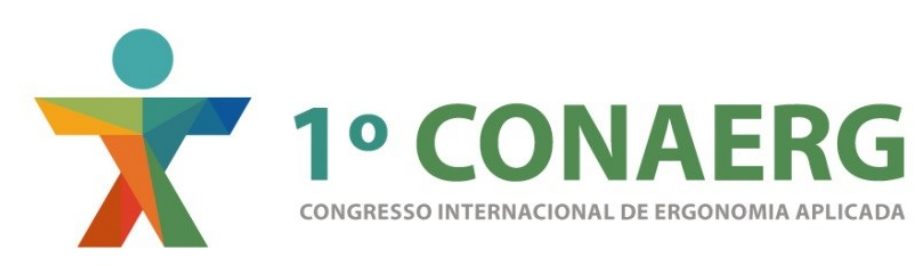

\title{
ACESSIBILIDADE EM PASSAGENS SOBRE VIAS DE GRANDE TRÁFEGO: ESTUDO DA PASSARELA NO CAMPUS RECIFE DA UNIVERSIDADE FEDERAL DE PERNAMBUCO
}

\author{
Valéria de Barros Viana (1) \\ Rayanne Lima (2) \\ (1) Universidade Federal de Pernambuco, Doutora em Arquitetura e Urbanismo \\ e-mail: valeriaviana@hotmail.com \\ (2) Universidade Federal de Pernambuco, Discente do curso de Arquitetura e Urbanismo \\ e-mail: rayanne.dglima@gmail.com
}

\begin{abstract}
RESUMO
O trabalho consta da análise de passarelas nas vias de trânsito intenso de rodovias federais urbanas, através de pesquisa na passarela sobre a BR 101 Sul, adjacente a Universidade Federal de Pernambuco - Recife, na qual foram avaliadas as condições de acessibilidade. Especificamente, foram estudadas as condições de uso e, como elementos de análise, os fatores intervenientes no grau de satisfação e exigências dos usuários. O resultado da pesquisa indicou que os usuários caracterizam e dimensionam as dificuldades que enfrentam, embora não conheçam a aplicabilidade da norma relativa aos seus direitos, nem a quem recorrer para solucionar problemas enfrentados no local.
\end{abstract}

Palavras chave: arquitetura, acessibilidade urbana, passarelas em rodovias federais

\begin{abstract}
The work consists on the catwalks analysis in heavy traffic of federal highways, through the research about a particular case on the BR 101 South, adjacent to Federal University of Pernambuco - Recife, in which were evaluated the accessibility conditions. It specifically studied the using conditions and, as elements of analysis, the factors involved in the satisfaction degree and needs of users. The survey results indicated that the users characterize and measure some difficulties they face, although it doesn't meet the applicability of the standard for their rights, or to whom they should turn to address problems on site.
\end{abstract}

Keywords: architecture, urban accessibility, walkways on federal highways.

\section{INTRODUÇÃO}

Algumas capitais brasileiras apresentam vias estruturais para as necessidades de tráfego de travessia ou de ligações de pontos estratégicos para evitar o adensamento na cidade. As vias intraurbanas que margeiam áreas habitacionais ou de uso misto, não comportam uma padronização no tratamento da travessia que, sem as passarelas, concorrem para que no 
Brasil as condições das vias - sinalização, trechos de travessia, etc. - sejam responsáveis por $47 \%$ dos atropelamentos com vítimas fatais (IPEA, 2008). Gerenciadas através da administração direta, por delegação ou através de concessionárias de iniciativa privada, as rodovias federais incluem na gerência a garantia quanto à segurança na travessia dos moradores ou ainda dos transeuntes com destinos variados. As rodovias federais na área urbana estão sob o regime de administração direta do Departamento Nacional de Infraestrutura e Transporte - DNIT -, o qual é responsável pela construção, manutenção e adequação da capacidade e melhoramentos de passarelas e seus entornos, a exemplo de encargos como alargamento de acostamento, melhoria de estruturas, incorporação de vias para pedestres, e inclusão de etapas de construção e reabilitação de estruturas temporárias. De acordo com o regulamento definido pelo órgão competente (DNIT, 2006) as diretrizes norteadoras de um projeto de passarela para pedestres, constantes nas DIRETRIZES BÁSICAS PARA ELABORAÇÃO DE ESTUDOS E PROJETOS RODOVIÁRIOS, objetivam garantir aos pedestres conforto, segurança e facilidade de acesso; observar as prescrições da Norma ABNT NBR 9050/2015; etc. Sobre a sinalização, recomenda que a área contígua à passarela seja fartamente sinalizada através de sinalização horizontal e vertical, e que sejam utilizadas placas indicativas e de advertência para pedestres e motoristas. Também torna claro parâmetros e padrões para os elementos de proteção ao pedestre-usuário e geométricos intervenientes no projeto de passarelas sobrejacentes - aquelas em nível superior a superfície da(s) pista(s) de rolamento) a exemplo de:

- Elementos de proteção ao pedestre-usuário: tabuleiro da seção horizontal com largura mínima de $2 \mathrm{~m}$ e guarda-corpo com altura mínima de $1 \mathrm{~m}$, construído em concreto armado ou aço, fixado ao vigamento principal do tabuleiro, de forma a assegurar resistência mínima ao impacto de $80 \mathrm{kgf}$ contra o corrimão,

- Pisos: obrigatoriamente em material antiderrapante,

- Bloqueio das pistas de rolamento ao acesso de pedestres: a área adjacente ao local do projeto, bloqueada por alambrado com altura mínima de $2 \mathrm{~m}$ e fixado junto às bordas externas dos acostamentos, com extensão de pelo menos $20 \mathrm{~m}$ para cada lado do eixo longitudinal da obra, induzindo o pedestre à travessia pela passarela.

Com base na regulamentação e na importância das passarelas nas rodovias urbanas, foi desenvolvido este trabalho na área de acessibilidade física, focado nas condições gerais de acesso e uso exigidas pelos usuários tendo em vista aspectos de segurança, autonomia na mobilidade e conforto, a partir do estudo de uma passarela que conecta o entorno da Superintendência de Desenvolvimento do Nordeste - SUDENE - e arredores ao edifício de frente, que consta do Hospital das Clínicas da Universidade Federal de Pernambuco campus Recife - além de edificações comerciais adjacentes ao referido campus. Tendo em vista a importância desta passagem com base no significativo número de travessias diárias (diurna e noturna), foi estruturado este estudo com a inserção de uma pesquisa de opinião apenas com usuários que efetuaram no mínimo três travessias na referida passarela, possibilitando assim repassar informações quanto à forma de uso, às características físicas atuais, bem como opiniões sobre aspectos gerais deste acessório rodoviário, de forma a adequar-se às necessidades das pessoas, evitando assim a prática da travessia sob a passarela e, consequentemente, concorrendo para acidentes e óbitos na rodovia. $O$ referencial teórico utilizado constou da normativa do DNIT de 2006, da Norma Brasileira 9050 de 2015 e, na concepção dos instrumentos que foram utilizados junto aos usuários, modelos de testes avaliativos da psicologia ambiental (ARAGONÉS, 2002; OKAMOTO, 2002) e da ergonomia no ambiente construído (MORAES \& MONTALVÃO, 2007). Alguns aspectos ergonômicos das escadas, passarela e elevadores foram mencionados na caracterização física do local e dos elementos e sistemas. 


\section{MATERIAIS E MÉTODOS}

A pesquisa foi realizada no entorno e em toda a dimensão da passarela que une as calçadas da Sudene ao Hospital das Clínicas da UFPE, principal fator do acesso da maioria dos pedestres entrevistados. No levantamento de dados foram considerados alguns critérios preestabelecidos antes da tomada de dados a respeito dos usuários:

- Estes deveriam obrigatoriamente estar deslocando-se ou terminando de cruzar a passarela no momento da entrevista. Foram excluídas as pessoas em trânsito pela calçada do Hospital das Clínicas ou no lado oposto a esta, bem como aquelas que estavam caminhando para locais adjacentes com intenção de não cruzar a BR 101 Sul;

- Sem considerar o destino final dos transeuntes, só seriam entrevistados aqueles que fizessem uso da passarela, independentemente do número de vezes, sendo considerados como participantes somente aqueles que a tivessem cruzado pelo menos três vezes, já que no pré teste foi registrado que todos se sentem inseguros na primeira vez de uso e, em consequência, frequentemente optam por efetivar a travessia por outro caminho;

- Os dados seriam coletados através de entrevistas elaboradas após o pré teste o qual permitiria a obtenção de categorias a serem utilizadas na estruturação do questionário definitivo da entrevista, bem como na observação direta sistemática que forneceriam critérios adicionais no momento do levantamento de dados junto ao usuário.

Ressalva-se que esta pesquisa foi efetivada após um ano de ter sido tema de um exercício de aplicação da NBR 9050/2014, por alunos da disciplina de Acessibilidade do curso de Arquitetura e Urbanismo da UFPE, em duas passarelas existentes no referido campus. No segundo semestre de 2015, foi atualizado o levantamento das condições físicas através de registro fotográfico do entorno, das condições gerais dos elevadores e dos componentes estruturais da passarela, bem como alguns elementos e sistemas construtivos de apoio inseridos no âmbito da acessibilidade física, referenciada pela norma da ABNT atualizada NBR 9050/2015 - o Decreto n 5.296 de 2 de dezembro de 2004, e NBR 9077/2010 (Saídas de emergência). Enfatiza-se ainda que diante das condições gerais das passarelas quanto aos aspectos de conforto mencionados pelos usuários na fase de pré testes, foram efetivadas medições de nível sonoro (ABNT 10152:1987) com um decibelímetro DT-8852 classe 2 (calibrador e referência com o decibelímetro MSL 1325 A) para avaliar as condições de ruído e seu grau de incômodo no local, haja visto sua localização numa BR de trânsito tão intenso. Na segunda etapa foram efetivadas as entrevistas através de questionários com perguntas fechadas, segundo os critérios selecionados na fase do pré teste. Para a observação direta, foi utilizado um bloco de anotações na forma de ficha a ser preenchida pelos pesquisadores e para cada usuário. Foram entrevistadas trinta pessoas que foram questionadas sobre as condições de uso do objeto de pesquisa, e suas respostas foram registrados por meio de fichas. Estas permitiram estruturar o perfil dos entrevistados, com definição do sexo, das condições físicas de mobilidade, do tipo de deficiência, da idade e das distintas formas de uso. Durante os turnos matutino e vespertino foram alternadas as entrevistas e os registros de comportamentos observáveis durante a mobilidade dos participantes na forma de passeio acompanhado. Na terceira etapa foram tabulados, analisados e discutidos os dados levantados e, finalmente elaboradas algumas recomendações. 


\section{ASPECTOS FÍSICOS DA PASSARELA}

A passarela em estudo cruza a BR 101 no trecho da Cidade Universitária em que está localizado o Hospital das Clinicas e, frontalmente, o edifício da SUDENE, sendo a travessia por esta passarela também utilizada por pessoas que se deslocam para ruas adjacentes ao Hospital, local de intenso movimento, seja comercial, institucional, educacional e/ou de serviço especializado (cemitério) no referido bairro (foto 1). Reformada em 2012 pelo Departamento Nacional de Infraestrutura em Transportes - DNIT -, até o final de 2015 ainda não havia sido feita a manutenção segundo laudo de licitação oriundo do próprio órgão.

Foto 1 - Passarela na BR 101 que liga o entorno da SUDENE ao Hospital das Clínicas

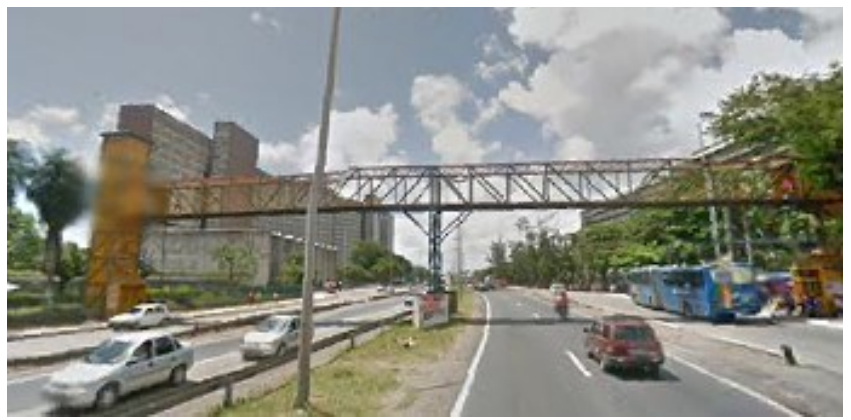

Fonte: Arquivo pessoal

Os componentes da passarela em estudo constam de duas torres com elevadores acionados por dois empregados, uma faixa de deslocamento sobre via (foto 2), escadas laterais e demais elementos construtivos. $O$ trecho da passagem que permite 0 deslocamento entre elevadores ou escadas, deve possuir uma largura que é definida em função do volume de pedestres estimado para os horários de maior movimento (NBR 9050:2015, item 6.13). Neste sentido e até o presente momento, encontra-se de acordo com a referida norma. $O$ ruído durante o levantamento físico pareceu ensurdecedor, entretanto, foi registrado uma variação de 66,2 decibels (no interior do elevador e sem o acréscimo do ruído de fundo oriundo do ventilador) e de 78,3 a 98,5 decibels (centro da passarela). Ressalta-se ainda que o resultado das medições nos elevadores foram diferenciadas em decorrência da configuração do projeto arquitetônico relacionado à direção dos ventos dominantes de sudeste predominantes em Recife.

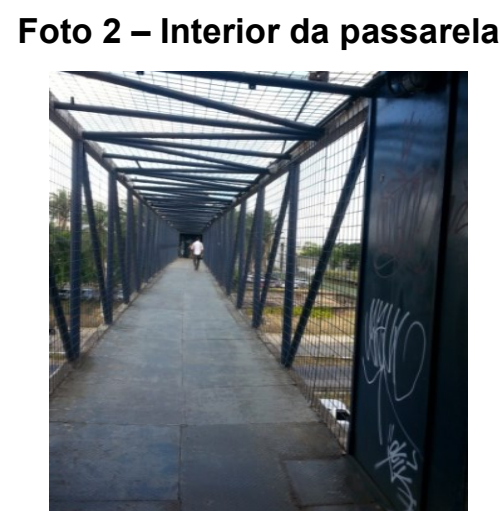

Fonte: Arquivo pessoal

A passarela é constituída de uma estrutura metálica a qual encontra-se visivelmente deteriorada pela ação das intempéries e da maresia que "enferruja" o material em pontos estratégicos que exigem o uso das mãos ou do guarda corpo, vigas transversais de 
sustentação soltas, bem como algumas placas metálicas do piso contendo orifícios que permitem a passagem de um pé humano (foto 3). Não existe sinalização de advertência nem de orientação para indicar escadas ou acesso aos elevadores. Os corrimãos (quando existentes, uma vez que existe patamar sem corrimão nem guarda corpo) não tem placas de orientação ou escrita em Braille nos corrimãos. Existe entre espelho e degraus um vazio de dimensões que geram desconforto nos usuários, embora a dimensão de pisos e larguras mínimas dos degraus e patamares encontrem-se de acordo com o que recomenda a NBR 9050/2015.

\section{Foto 3 - Interior e acesso dos elevadores}

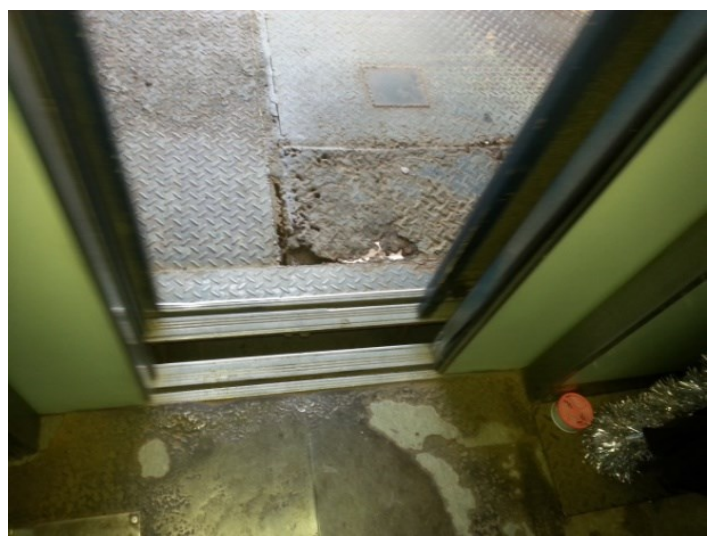

Fonte: Arquivo pessoal

$\mathrm{Na}$ calçada da SUDENE, o acesso ao elevador está sem manutenção, dificultando a saída do cadeirante - vale ressaltar que durante o trabalho foi registrado a urgência de ajuda externa para acesso aos elevadores- além de contar com um risco para o deficiente visual, uma vez que não há sinalização que o informe da existência do limite entre a calçada e a pista de rolamento da BR 101 (foto 4).

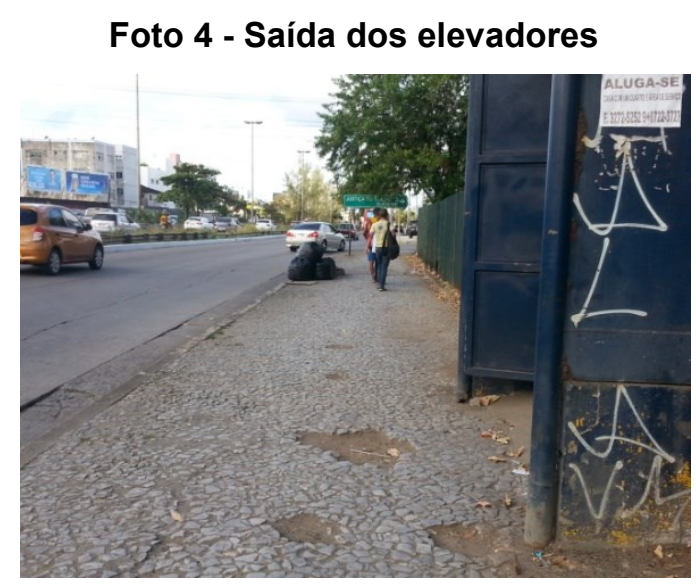

Fonte: Arquivo pessoal

Ainda na lateral da SUDENE, ocorre o rebaixamento do piso na calçada (foto 5), que vai dar em "lugar nenhum", já que o sentido oposto está fechado por cerca de metal a 60 centímetros do solo, no canteiro central, o que dificulta a passagem daqueles que preferem fazer a travessia a pé. O que acontece frequentemente é que alguns atravessam a cerca e, ao concluir o percurso, põe suas vidas em risco: fato que ocorre constantemente, segundo depoimentos de vendedores que trabalham no entorno do Hospital das Clínicas. Outra alternativa utilizada para a travessia é caminhar por vários quarteirões até encontrar um 
semáforo e uma faixa de pedestres, próximo à avenida Caxangá, e fazer o retorno até o local de destino - Hospital das Clínicas, interior do campus da UFPE ou áreas externas de uso misto.

\section{Foto 5 - Rebaixamento da calçada para vias central e laterais}

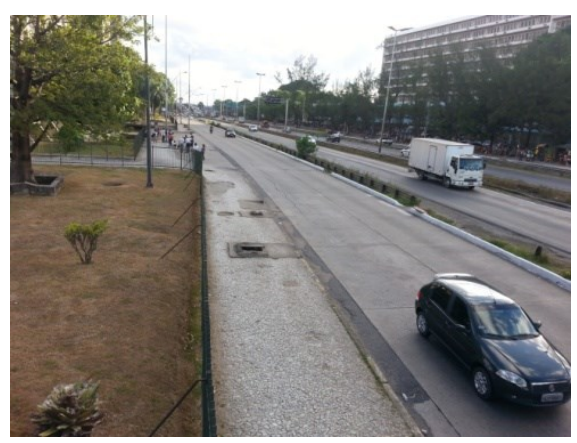

Fonte: Arquivo pessoal

No entorno do Hospital Universitário ao lado da passarela, estende-se grande número de barracas, bem como uma parada de ônibus com calçada medindo 26 centímetros de altura e sem rampa de acesso, local onde deveria intermediar o acesso das pessoas ao Hospital das Clínicas, cuja entrada consta de uma passagem com largura abaixo do que especificas a norma (NBR 9050 - 120 a 200 centímetros) e rampas danificadas revestidas de concreto e com inclinações aproximadas de 9,5\% (também acima da Norma). Apresentam 100 centímetros de largura, abaixo da mínima recomendada (120 centímetros), e seus trajetos não permitem continuidade, dificultando os deslocamentos de todas as pessoas, principalmente de cadeirantes e deficientes visuais. Também não comportam grade e guarda corpo, além de apresentar buracos e valas profundas e/ou abertas, bem como de outros problemas decorrentes da falta de manutenção periódica.

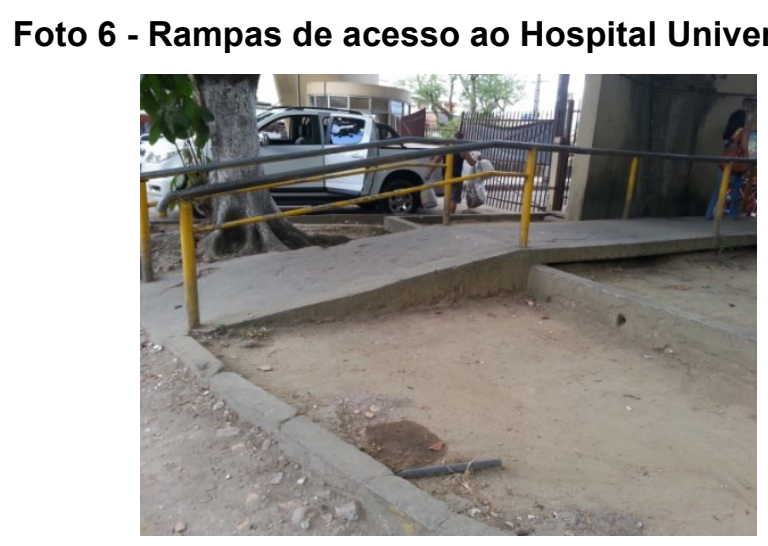

Fonte: Arquivo pessoal

No que diz respeito a pisos com sinalização tátil, nota-se apenas a existência dos de "advertência". Dessa forma, atesta-se que a norma foi aplicada de forma parcial, já que não existe um sistema contínuo e completo de sinalização, o que não faz muito sentido para o deficiente visual, nem funciona para o cadeirante ou pessoas com mobilidade reduzida. Não há corrimão sinalizado e as seções desses elementos componentes variam entre 6 a 18 centímetros: situação incompatível com o que é recomendado pela norma. A estrutura metálica encontra-se em estado de decomposição devido à maresia, ameaçando o usuário com danos que vão de ferimentos leves a graves por estarem cobertos pela ferrugem. 


\section{CARACTERIZANDO OS USUÁRIOS}

Entre os 33 transeuntes entrevistados, todos já utilizaram a passarela pelo menos três vezes. Foram consultados 14 homens e 19 mulheres com idades variando entre 18 a 78 anos. Seis deles $(18,1 \%)$ apresentam uma deficiência motora, seja temporária ou permanente na forma de artrose, artrite ou uma restrição motora em uma das pernas decorrentes das citadas doenças as quais os conduzem a um tratamento de reabilitação no Hospital das Clínicas - Hospital Universitário. Apenas um cadeirante foi entrevistado, já que os demais não quiseram participar da pesquisa. Também participaram do trabalho, três pessoas com sobrepeso e, portanto com mobilidade reduzida devido à extensão da passarela e as condições do percurso, e o restante não apresentou queixa com relação à saúde física. Dezesseis dos entrevistados (48\%) cruzam esta importante rodovia todos os dias uma vez que trabalham no bairro ou no Hospital das Clínicas. Dois não quiseram responder, e o restante $(45 \%)$ atravessa a rodovia para tratamento médico, consulta ou exames de rotina no referido Hospital. De forma geral, a má condição física da passarela é a causa principal de realização da travessia alternativa por baixo da mesma. Alguns entrevistados enfatizaram a ocorrência frequente de acidentes fatais neste trecho da rodovia e que, segundo vários depoimentos, não são registrados, principalmente em caso de óbitos. Entre os principais problemas apontados para evitar a passarela, ou usá-la com restrições, foram citados:

- Falta de manutenção da estrutura geral: vigas soltas, pisos corroídos pela maresia, malha de segurança muito fina e deformada por ação do sol;

- Falta de segurança no final da tarde e à noite em decorrência de assaltos;

- Deficiência no sistema de iluminação, principalmente à noite. As lâmpadas são roubadas e não há reposições, nem um sistema de segurança que as mantenham no local;

- Piso com desgaste que permite a entrada de um pé de adulto;

- Falta de guarda corpo em uma das escadas;

- Buracos e pontas afiadas nos corrimãos, provocando cortes ou desconforto ao tato;

- Vibrações que geram desequilíbrio no caminhar sobre a passarela, além de ruídos na mesma, que passam a sensação de que a estrutura está prestes a desmoronar.

De forma geral as dimensões e sinalizações correspondentes aos elementos constitutivos da passarela ou encontram-se em conflito com as normas ou inexistem, tornando-a na percepção dos usuários, um elemento de estresse pois consta como um "mal necessário".

\section{DISCUSSÃO DOS RESULTADOS}

A partir dos dados relacionados entre si, entre aqueles recopilados da bibliografia consultada, entre os fornecidos através dos usuários, e finalmente entre aqueles obtidos através de observação direta, considera-se que:

- O método permitiu caracterizar as exigências do usuário relativas às características exigidas para as passarelas;

- Os usuários definem com clareza a situação de desconforto e insegurança gerados pelas condições precárias atuais da passarela analisada, mas não tem noção sobre quem a administra para enviar as reclamações, além de desconhecer as legislações referentes ao objeto de pesquisa, as quais permitam assegurar seus direitos quanto às condições exigidas para as passarelas tendo em vista sua segurança; 
- Apesar do grau de desconforto térmico mencionado no momento do passeio acompanhado e durante as entrevistas, as quais foram concluídas durante o verão, estes não foram registrados por instrumentos, mas através das atitudes, das respostas e da forma como as pessoas atravessam a passarela. Pode-se concluir que, tanto a passagem, como elevadores e escadas, são termicamente desconfortáveis em decorrência da insolação direta ou indireta (nos elevadores servidos por pequenos ventiladores);

- As medições das fontes de ruídos externas, geradas pelos veículos de cargas e transportes na rodovia, registraram níveis compatíveis com o desconforto acústico referenciado pela Norma. Entretanto, conforme as respostas durante as entrevistas e nos passeios, as vibrações na estrutura metálica da passarela - no momento da passagem dos carros - incomodam muito mais que o ruído ambiental produzido no entorno pelos automóveis, pelas pessoas que utilizam o comércio informal dos barraqueiros, e outras fontes de ruídos. Foi registrado que a vibração está associada ao medo de desmonte da estrutura, sendo por esta razão, mais nociva aos usuários se comparados aos elevados níveis de ruído aéreo do tráfego abaixo da passagem.

- A iluminação artificial existente, embora seja suficiente se correlacionada à norma, não evita os assaltos, o que culmina com a travessia das pistas à noite, gerando insegurança, possibilidade de acidentes e, na maioria dos casos, o deslocamento do usuário - repulsão e transferência espacial da passarela para outros caminhos alternativos. A iluminação artificial também torna-se um problema uma vez que, devido ao roubo das fontes de luz as quais não comportam um sistema de segurança adequado à realidade local, consta de um sistema que dificulta a acuidade visual que, mesmo deficiente, mostra-se possível pela existência dos postes existentes para iluminação da rodovia;

- O rebaixamento nas calçadas em direção à rodovia, além de não permitir ultrapassagem (na situação de travessia indevida por baixo da passarela), também possibilita incidentes na área central, pois o transeunte tem que pular a faixa metálica que margeia esta área. Este fato em particular demonstra que a norma está sendo cumprida de forma equivocada gerando risco de vida para o usuário, já que existe mas não permite a mobilidade segura para o usuário por falta de continuidade - usabilidade integrativa;

- As péssimas condições na estrutura danificada pela maresia e pela falta de uma manutenção periódica são fontes de acidentes, bem como de óbito - maior ocorrência em pessoas com baixa ou sem visão -, devido à ausência de guarda corpo nas escadas da passarela.

\section{CONCLUSÃO}

Este trabalho permitiu uma visão mais específica sobre as qualidades exigidas para as passarelas de forma a atender uma população de pedestres que frequentemente prefere uma travessia sob as mesmas, como única alternativa. Concluindo, foram relacionadas algumas recomendações com visas a melhoria das condições deste acessório localizado em rodovias em áreas urbanas:

a) Gerar meios de informação para que o usuário saiba como buscar soluções alternativas para os problemas detectados nas passarelas;

b) Concatenar as legislações com as condições do local de forma a adequá-las às necessidades dos usuários em realidades específicas; 
c) Estabelecer uma regulamentação na forma de protocolo acerca da manutenção $d$ a estrutura das passarelas, tendo em vista as condições climáticas locais e seus efeitos nos materiais;

d) Construir passarelas com condições de uso para os deficientes visuais e demais situações especiais, de forma integrada às características de recobrimento do solo e elementos componentes, além da garantia na continuidade da mobilidade em todo o deslocamento de forma integrada às circulações adjacentes;

e) Estabelecer engates amortecedores no sistema estrutural e construtivo da passarela que permitam a atenuação das vibrações - ruídos de baixa frequência - sentidas em seu interior, além do incremento nos sistemas de absorção e isolamento nos elevadores;

f) Prover as escadas com sistemas de segurança para as fontes de luz;

g) Estabelecer formas de controle para a segurança do usuário a noite;

h) Gerar campanhas educativas contendo entre outros temas, de um sistema de informação sobre os riscos e perigos das travessias forçadas e por baixo da passarela, e o modo correto de uso das mesmas para os usuários com distintas diferenças motoras e/ou sensoriais ou com mobilidade reduzida.

\section{REFERÊNCIAS}

ARAGONÉS, J;. I. Psicologia Ambiental. Ed. Pirâmide, 2002.

ASSOCIAÇÃO BRASILEIRA DE NORMAS TÉCNICAS. NBR 10152 - Níveis de ruído para conforto acústico. Rio de janeiro: ABNT, 1987.

ASSOCIAÇÃO BRASILEIRA DE NORMAS TÉCNICAS. NBR 9050 - Acessibilidade na edificação nos transportes. Rio de Janeiro: ABNT, 2015.

ATKINS, S. et all. The influence of street light on crime and fear or crime. Southampton: University of Southampton, 1991. Disponivel em:

www.celfosc.org/new/sputhampton.htm. Acesso em: 12 de 03 de 2016.

MINISTÉRIO DOS TRANSPORTES. Departamento Nacional de Infraestrutura de Transportes, Diretrizes básicas para elaboração de estudos e projetos rodoviários: escopos básicos / instruções de serviço, 3ª edição. Rio de Janeiro, 2006.

MINISTÉRIO DOS TRANSPORTES. Departamento Nacional de Infraestrutura de Transportes, Terminologia rodoviárias usualmente utilizadas, Versão 1.1, 2007

MORAES, A. M. de MONTALVÃO, C. Ergonomia: conceitos e aplicações. $3^{a}$ edição. Rio de Janeiro:2AB, 2007.

OKAMOTO, Jun. Percepção ambiental e comportamento. São Paulo: Ed. Mackenzie, 2002. 